\title{
Benzyne-mediated rearrangement of 3-(2-pyridyl)-1,2,4-triazines into 10-(1H-1,2,3-triazol-1-yl)pyrido[1,2-a]indoles
}

\author{
Igor L. Nikonov ${ }^{a}$, Dmitry S. Kopchuk ${ }^{\mathrm{a}, \mathrm{b}}$, Igor S. Kovalev ${ }^{\mathrm{a}}$, Grigory V. Zyryanov ${ }^{\mathrm{a}, \mathrm{b}, *}$, Albert F. Khasanov ${ }^{\mathrm{a}}$, \\ Pavel A. Slepukhin ${ }^{\mathrm{b}}$, Vladimir L. Rusinov ${ }^{\mathrm{a}, \mathrm{b}}$, Oleg N. Chupakhin ${ }^{\mathrm{a}, \mathrm{b}}$ \\ ${ }^{a}$ Ural Federal University, 19, Mira St., 620002 Ekaterinburg, Russia \\ ${ }^{\mathrm{b}}$ Postovsky Institute of Organic Synthesis of RAS (Ural Branch), 22/20, S. Kovalevskoy/Akademicheskaya St., 620990 Ekaterinburg, Russia
}

\section{A R T I C L E I N F O}

Article history:

Received 10 July 2013

Revised 22 August 2013

Accepted 12 September 2013

Available online 20 September 2013

Keywords:

Arynes

1,2,4-Triazines

Rearrangemen

1,2,3-Triazoles

Pyrido[1,2-a]indoles

\begin{abstract}
A B S T R A C T
The reaction between 5-R-6- $\mathrm{R}^{1}$-3-(2-pyridyl)-1,2,4-triazines and benzyne generated in situ in toluene under reflux results in the formation of $10-(1 H-1,2,3-$ triazol-1-yl)pyrido[1,2-a]indoles 3 in up to $60 \%$ yields instead of the expected $3-R-4-R^{1}-1-(2$-pyridyl)isoquinolines 2 . The crystal structure of product $\mathbf{3 c}$ and the proposed mechanism for the formation of $\mathbf{3}$ are reported.
\end{abstract}

(c) 2013 Elsevier Ltd. All rights reserved.
Aryne intermediates are of wide use as versatile tools for the synthesis of various heteroaromatic systems, ${ }^{1}$ including photoluminescent intercalators ${ }^{2}$ and other physiologically active compounds, such as alkaloids and their carbo- and heterocyclic analogs, ${ }^{3}$ and fluorescent sensors for nitroaromatics. ${ }^{4}$ At present, most of these compounds can be obtained via the one-step Diels-Alder reaction between various heteroaromatic dienes and cyclic (het)arynes as dienophiles. However, little attention has been given to the reactions of arynes as dienophiles and various cyclic azines as extremely active dienes, the so-called inverse electron demand Diels-Alder reactions. ${ }^{5}$ In particular, only a few cases of reactions between 1,2,4-triazines and benzyne to afford isoquinolines in low yields have been described. ${ }^{6}$ Moreover, only two cases have been reported for the formation of benzene-annelated analogs of highly promising 2,2'-bipyridine-type ligands ${ }^{7}$ by the one-step inverse electron demand Diels-Alder reaction between 5-phenyl-3-(2-pyridyl)-1,2,4-triazine and in situ generated benzyne under very harsh conditions: autoclave, toluene, $140{ }^{\circ} \mathrm{C},{ }^{8}$ or by heating in $o$-dichlorobenzene at $160{ }^{\circ} \mathrm{C} .{ }^{9}$

In addition, we have developed an alternative synthetic approach toward aryl-substituted 1-(2-pyridyl)isoquinolines via the Diels-Alder reaction of 3-(2-pyridyl)-1,2,4-triazines with

\footnotetext{
* Corresponding author. Tel.: +7 343375 4501; fax: +7 3433740458.

E-mail address: gvzyryanov@gmail.com (G.V. Zyryanov).
}

1-morpholinocyclohexene followed by aromatization of the resultant tetrahydrosoquinolines. ${ }^{10}$

Herein we report the results of our study on the reactions of het(aryl)-substituted-1,2,4-triazines with benzyne, which was aimed at the development of a convenient method for the onepot conversion of 1,2,4-triazines into isoquinolines, including benzene-annelated 2,2'-bipyridyl ligands.

Aryl-substituted 3-(2-pyridyl)-1,2,4-triazines 1a-c were synthesized according to published methods ${ }^{11}$ and were used as the starting materials (Scheme 1 ).

Surprisingly, in the reactions between 1a-c and benzyne generated in situ from 2-aminobenzoic acid and isoamyl nitrite ${ }^{12}$ in toluene under reflux, we did not observe the formation of the expected pyridyl-isoquinolines $\mathbf{2}$.

Analysis of the ${ }^{1} \mathrm{H}$ NMR spectra of the obtained products and compound 2a, prepared by an alternative method, ${ }^{10}$ did not show any matches, that is, the resonances of the aromatic protons in the products were downfield compared to the similar resonances observed for compound 2a. In addition, according to ESI-mass spectrometry there were four nitrogen atoms in molecules of products 3a-c versus two nitrogen atoms in product $\mathbf{2 a}$. The initial suggestion that the reaction of compound $\mathbf{1}$ and benzyne afforded only the 3,6-cycloaddition products without elimination of a nitrogen molecule was ruled out by the results of ${ }^{13} \mathrm{C}$ NMR measurements: there were no signals due to $\mathrm{sp}^{3}$-hybridized carbons in the ${ }^{13} \mathrm{C}$ NMR spectra for products $\mathbf{3 a - c}$. In order to confirm the structures 


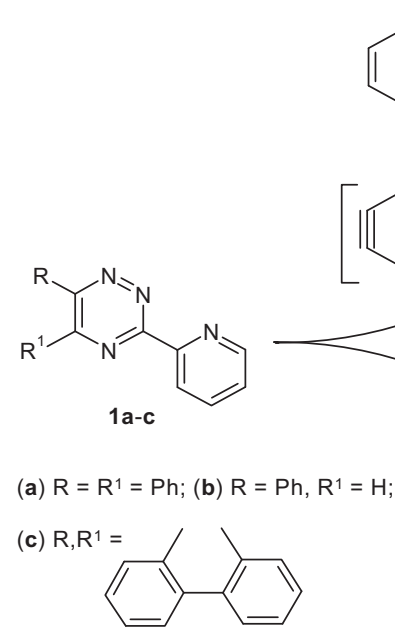

Scheme 1. Benzyne-mediated transformation of 3-(2-pyridyl)-1,2,4-triazines into 10-(1H-1,2,3-triazol-1-yl)pyrido[1,2-a]indoles. Reagents and conditions: (i) toluene, isoamyl nitrite, $110^{\circ} \mathrm{C}, 1.5 \mathrm{~h}$.

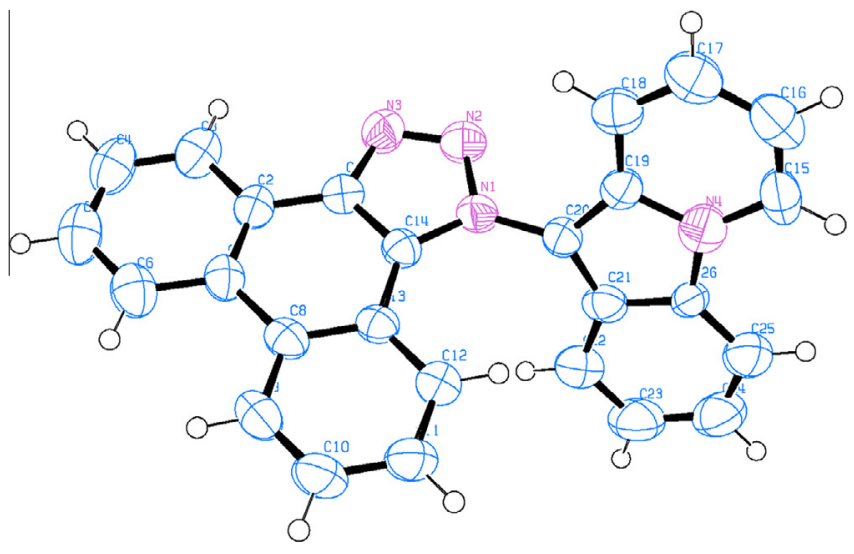

Figure 1. ORTEP view of the crystal structure of 3c. Displacement parameters at $50 \%$ of the electron density. Selected bond distances $(\AA)$ and angles $\left({ }^{\circ}\right): N(1)-C(14)$ $1.359(2), \mathrm{N}(1)-\mathrm{N}(2)$ 1.371(2), N(1)-C(20) 1.409(2), C(1)-N(3) 1.355(2), N(2)-N(3) $1.306(2), \mathrm{N}(4)-\mathrm{C}(26) 1.385(2), \mathrm{N}(4)-\mathrm{C}(15)$ 1.401(2), N(4)-C(19) $1.400(2), \mathrm{C}(21)-$ $\mathrm{C}(26) 1.387(2), \mathrm{C}(25)-\mathrm{C}(26) 1.361(3), \mathrm{N}(3)-\mathrm{N}(2)-\mathrm{N}(1) 107.61(15), \mathrm{N}(2)-\mathrm{N}(3)-\mathrm{C}(1)$ 108.92(16), C(14)-N(1)-N(2) 109.54(16), C(14)-N(1)-C(20) 132.42(17), C(26)$\mathrm{N}(4)-\mathrm{C}(15)$ 130.2(2), C(26)-N(4)-C(19) 108.20(18), C(15)-N(4)-C(19) 121.5(2), $\mathrm{C}(25)-\mathrm{C}(26)-\mathrm{N}(4) \quad 128.7(2), \quad \mathrm{C}(25)-\mathrm{C}(26)-\mathrm{C}(21) \quad 123.1(2), \quad \mathrm{N}(4)-\mathrm{C}(26)-\mathrm{C}(21)$ 108.23(18).

of products 3a-c, we performed X-ray crystal analysis of a single crystal of compound $3 \mathbf{c}$ (Fig. 1). The X-ray diffraction data obtained revealed the structure of product $3 c$ as $10-(1 H-1,2,3-$ triazol-1yl)pyrido[1,2-a]indole. ${ }^{13}$

Based on the structures of products $\mathbf{3 a - c}$ a plausible mechanism can be suggested (Scheme 2). Thus, the initial step involves the concerted or step-wise [2+3] cycloaddition of benzyne at position 3 of the 1,2,4-triazine and the nitrogen atom of the pyridine substituent to afford two spiro-compounds (I and II). It is obvious that both these intermediates are extremely unstable due to steric hindrance. As a result, cleavage of the N3-C4 bond occurs to form intermediate III. Finally, due to the presence of positive and negative charges on the nitrogen atoms, a new $\mathrm{N}-\mathrm{N}$ bond is generated and the final product $\mathbf{3}$ is formed.

The mechanism suggests that in order to govern the transformation of the 1,2,4-triazine into a 1,2,3-triazole ring it is necessary to introduce a 2-pyridyl substituent at position 3 of the 1,2,4-triazine ring. To confirm this, we carried out the reaction between 3,5,6-tri-<smiles>[R]C1=NN=NC2(c3ccccc3-c3ccccc3)NC([R])C([R])N=NC12c1ccccc1</smiles>

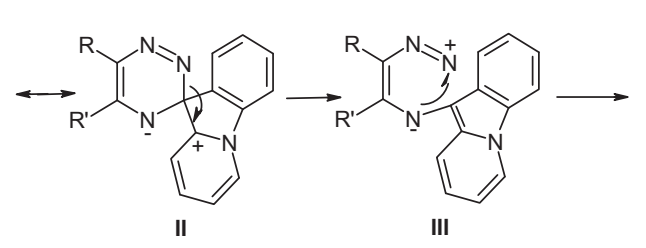<smiles>[R]c1nnn(-c2c3ccccc3n3ccccc23)c1[R]</smiles>

3

Scheme 2. A plausible mechanism for the benzyne-mediated rearrangement of 3(2-pyridyl)-1,2,4-triazines into 10-(1H-1,2,3-triazol-1-yl)pyrido[1,2-a]indoles.

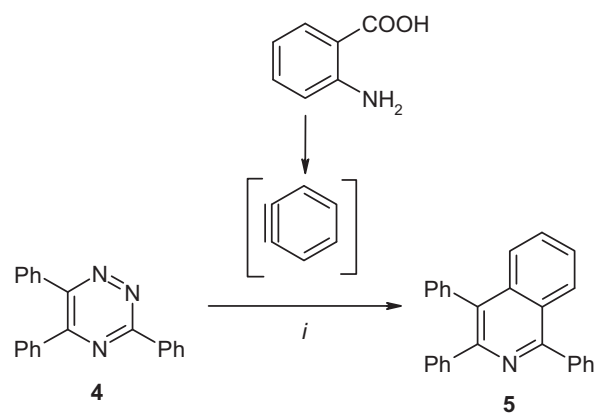

Scheme 3. The formation of 1,3,4-triphenylisoquinoline. Reagents and conditions: (i) toluene, isoamyl nitrite, $110^{\circ} \mathrm{C}, 1.5 \mathrm{~h}$.

phenyl-1,2,4-triazine (4) $)^{14}$ (an aryl-containing analog of compound 1a) and benzyne (Scheme 2), under the same conditions.

The only product observed in this reaction was triphenylisoquinoline 5, and no 1,2,3-triazole was isolated. All the spectral data obtained for this compound were in agreement with those reported previously. ${ }^{15}$ Thus, the presence of a 2-pyridyl substituent at position 3 of the 1,2,4-triazine is necessary for the transformation of the 1,2,4-triazine into a 1,2,3-triazole (Scheme 3).

In summary, a non-trivial method for the synthesis of $10-(1 \mathrm{H}-$ 1,2,3-triazol-1-yl)pyrido[1,2-a]indoles 3 has been reported. Pyrido[1,2-a]indoles are important in terms of their biological activity, in particular, cytostatic, ${ }^{16}$ antiviral, ${ }^{17}$ antitumor, ${ }^{18}$ etc. The preparation of these compounds by other synthetic approaches, ${ }^{19}$ including reactions with arynes, ${ }^{20}$ is still rare. A plausible mechanism for this transformation has been suggested, and the necessity for a 2-pyridyl substituent at position 3 of the 1,2,4-triazine ring was confirmed.

\section{Acknowledgments}

This work was supported by the Russian Ministry of Education (State Contracts Nos. 14.740.11.1020 and 14.A18.21.0817), RFBR (Grant No. 12-03-31726) and the Council for grants of the President of Russian Federation (Grant No. MK-1511.2013.3).

\section{Supplementary data}

Supplementary data associated with this article can be found, in the online version, at http://dx.doi.org/10.1016/j.tetlet.2013. 09.042. 


\section{References and notes}

1. (a) Kovalev, I. S.; Kopchuk, D. S.; Zyryanov, G. V.; Slepukhin, P. A.; Rusinov, V. L.; Chupakhin, O. N. Chem. Heterocycl. Compd. 2012, 48, 536; (b) Dubrovskiy, A. V.; Markina, N. A.; Larock, R. C. Org. Biomol. Chem. 2013, 11, 191.

2. Tadross, P. M.; Stoltz, B. M. Chem. Rev. 2012, 112, 3550.

3. Gampe, C. M.; Carreira, E. M. Angew. Chem., Int. Ed. 2012, 51, 3766.

4. (a) Zyryanov, G. V.; Palacios, M. A.; Anzenbacher, P., Jr. Org. Lett. 2008, 10, 3681; (b) Anzenbacher, P., Jr.; Mosca, L.; Palacios, M. A.; Zyryanov, G. V.; Koutnik, P. Chem. Eur. J. 2012, 18, 12712.

5. (a) Foster, R. A. A.; Willis, M. C. Chem. Soc. Rev. 2013, 42, 63; (b) Boger, D. L. Chem. Rev. 1986, 86, 781.

6. (a) d'A Rocha Gonsalves, A. M.; Melo, T. M. V. D.; Melo, T. M. V. D. P.; Gilchrist, T. L. Tetrahedron 1992, 48, 6821; (b) Dhar, R.; Huhnermann, W.; Kampchen, T.; Overheu, W.; Seitz, G. Chem. Ber. 1983, 116, 97.

7. (a) Sasse, W. H. F. Org. Synth. 1973, 5, 102; (b) Reedijk, J. In Comprehensive Coordination Chemistry: Pergamon: Oxford, 1987: Vol. 2, p. 73; (c) Kaes, C. Katz, A.; Hosseini, M. W. Chem. Rev. 2000, 100, 3553.

8. Kopchuk, D. S.; Zyryanov, G. V.; Kovalev, I. S.; Egorov, I. N.; Rusinov, V. L.; Chupakhin, O. N. Chem. Heterocycl. Compd. 2013, 48, 1871.

9. Diring, S.; Retailleau, P.; Ziessel, R. Tetrahedron Lett. 2007, 48, 8069.

10. Kopchuk, D. S.; Kovalev, I. S.; Khasanov, A. F.; Zyryanov, G. V.; Slepukhin, P. A. Rusinov, V. L.; Chupakhin, O. N. Mendeleev Commun. 2013, 23, 142.

11. (a) Case, F. H. J. Org. Chem. 1965, 30, 931; (b) Kozhevnikov, V. N.; Kozhevnikov, D. N.; Shabunina, O. V.; Rusinov, V. L.; Chupakhin, O. N. Tetrahedron Lett. 2005 46, 1791; (c) Kopchuk, D. S.; Zyryanov, G. V.; Kovalev, I. S.; Khasanov, A. F. Medvedevskikh, A. S.; Rusinov, V. L.; Chupakhin, O. N. Chem. Heterocycl. Compd. 2013, 49, 500 .
12. Huisgen, R.; Knorr, R. Tetrahedron Lett. 1963, 4, 1017.

13. Crystal data for 3c: monoclinic, space group $P 2_{1} / c, \quad a=12.4671(15)$, $b=8.6868(7), \quad c=17.444(2), \quad \beta=100.335(11)$ at $295(2) \mathrm{K}$ with $Z=4$, $R_{1}=0.0401, \mathrm{GOF}=1.007$. Crystallographic data for structure $3 \mathrm{c}$ have been deposited at the Cambridge Crystallographic Data Centre (CCDC 947859). Copies of the data can be obtained, free of charge, on application to CCDC, 12 Union Road, Cambridge CB2 1EZ, UK [fax: +40 (0) 1223336033 or e-mail: deposit@ccdc.cam.ac.uk].

14. Rostamizadeh, S.; Sadeghi, K. Synth. Commun. 2002, 32, 1899.

15. Alonso, R.; Campos, P. J.; Garcia, B.; Rodriguez, M. A. Org. Lett. 2006, 8, 3521.

16. (a) Ambros, R.; Von Angerer, S.; Wiegrebe, W. Arch. Pharm. 1988, 321, 481; (b) Ambros, R.; Schneider, M. R.; Von Angerer, S. J. Med. Chem. 1990, 33, 153.

17. Hudyma, T. W.; Zheng, X.; He, F.; Ding, M.; Bergstrom, C. P.; Hewawasam, P.; Martin, S. W.; Gentles, R. G. US Pat. Appl. Publ. 2006, 318, Cont.-In-Part of US Ser. No. 181, 639; Chem. Abstr. 2006, 145, 189063.

18. Orlemans, E. O. M.; Verboom, W.; Scheltinga, M. W.; Reinhoudt, D. N.; Lelieveld, P.; Fiebig, H. H.; Winterhalter, B. R.; Doublell, J. A.; Bibbyll, M. C. J. Med. Chem. 1989, 32, 1612.

19. (a) von Braun, N. Chem Ber 1937, 70, 1760; (b) Deegan, A; Rose, F. L. J. Org Chem. 1971, 2756; (c) Naredla, R. R.; Zheng, C.; Nilsson Lill, S. O.; Klumpp, D. A. J. Am. Chem. Soc. 2011, 133, 13169; (d) Soldatenkov, A. T.; Bagdadi, M. V.; Fomichev, A. A.; Prostakov, N. S. J. Org. Chem. USSR 1982, 18, 783; (e) Ohsawa, A.; Kawaguchi, T.; Igeta, H. Chem. Lett. 1981, 1737; (f) Gaster, L. M.; Wyman P. A. US Patent 005,998,409A, 1995; Chem. Abstr. 1995, 122, 265390.

20. Rogness, D. C.; Markina, N. A.; Waldo, J. P.; Larock, R. C. J. Org. Chem. 2012, 77, 2743. 